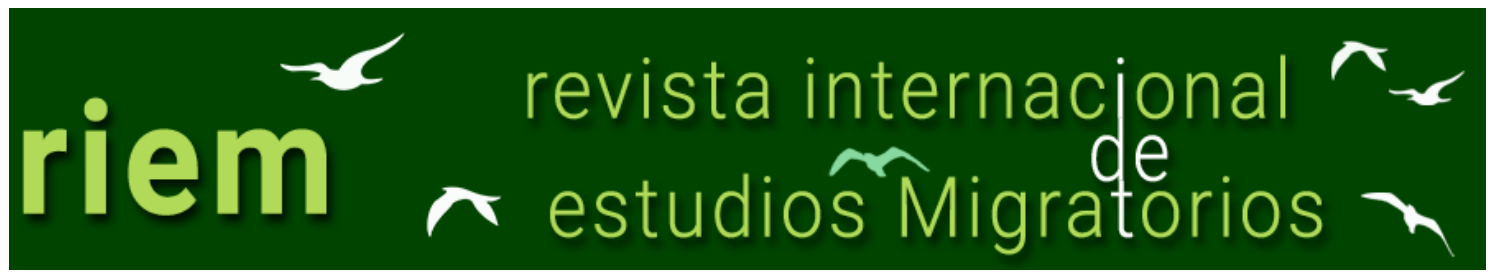

ISSN: 2173-1950

\title{
Migración, seguridad y falta de solidaridad en la Unión Europea
}

Raquel Rodríguez Camejo ${ }^{1}$

Resumen: La llamada crisis migratoria o crisis de refugiados del 2015, generó un importante e inconcluso debate entre instituciones y países integrantes de la UE, sobre cuál es la responsabilidad que tienen los Estados miembros en la política común migratoria. La gestión de la crisis impulsó el desarrollo de varias propuestas de la Comisión Europea para ordenar los flujos migratorios. Medidas destinadas a apoyar a los países de primera línea de llegadas de migrantes (reubicación de refugiados, reforma del SECA) y aumentar la seguridad para evitar la entrada y facilitar la expulsión de "migrantes irregulares" del territorio comunitario (ampliación Frontex, acuerdo UE Turquía). El artículo examina el enfoque securitario de la política migratoria europea, contextualizado en la lucha contra la inmigración irregular y la protección de los ciudadanos comunitarios en el espacio de libertad, seguridad y justicia de la UE, conjuntamente con el análisis de la falta de solidaridad y responsabilidad de los Estados miembros en resolver asuntos comunes de la política de inmigración. La investigación se apoya en los Tratados constitutivos de la UE, reuniones del Consejo Europeo y actos legislativos (reglamentos, directivas y recomendaciones) que se aplican a los Estados miembros en el marco de la lucha contra la inmigración irregular. El consecuente desacuerdo que trajo el incumplimiento del principio de solidaridad y reparto equitativo de responsabilidades (Art. 80, TFUE) por el que se rige la política común migratoria, así como la reintroducción de controles fronterizos en el Espacio Schengen desde 2015 por parte de algunos Estados miembros, cuestionan hasta dónde la defensa de la soberanía

1 PhD (candidata). Programa de Doctorado en Estudios Migratorios de la Escuela de Doctorado de Humanidades, Ciencias Sociales y Jurídicas (EDHCSJ), Universidad de Granada, Granada, España. rrguezcamejo@correo.ugr.es 
nacional y la falta de solidaridad de los Estados, convergen en una crisis de integración europea.

Palabras Clave: Unión Europea, política migratoria, inmigración irregular, seguridad, solidaridad en la UE. 


\title{
Migration, security and lack of solidarity in the European Union
}

\begin{abstract}
The known as migration crisis or refugees' crisis of 2015 generated an important and inconclusive debate between EU institutions and member countries, about what is the responsibility of the Member States in the common migration policy. Crisis management prompted the development of several proposals by the European Commission to order migration flows. Measures aimed at supporting the front-line countries of migrant arrivals (refugee relocation, SECA reform) and increasing security to prevent the entry and facilitate the expulsion of "irregular migrants" from Community territory (Frontex enlargement, agreement EU- Turkey). The article examines the security approach of European migration policy, contextualized in the fight against irregular immigration and the protection of community citizens in the area of freedom, security and justice of the EU, together with the analysis of the lack of solidarity and responsibility of the Member States to resolve common issues on immigration policy. The research is supported by the Treaties establishing the EU, meetings of the European Council and legislative acts (regulations, directives and recommendations) that apply to the Member States in the framework of the fight against irregular immigration. The consequent disagreement that led to the breach of the principle solidarity and equitable sharing of responsibilities (Art. 80, TFEU) by which the common migration policy is governed, as well as the reintroduction of border controls in the Schengen Area since 2015 by some Member States question how far the defense of national sovereignty and the lack of solidarity of the States converge in a crisis of European integration.
\end{abstract}

Keywords: European Union, migration policy, irregular immigration, security, solidarity in the EU. 


\section{Introducción}

Mientras escribo este texto, se está discutiendo a nivel interno y externo a los Estados miembros, el papel que está jugando la Unión Europea (UE) en la crisis sanitaria global del virus Covid-19. Una crisis descrita por algunos con terminología bélica - se lucha contra un enemigo invisible (virus) o no hemos tenido nada igual desde el fin de la Segunda Guerra Mundial - para dar cuenta de su magnitud. Se dice que esta crisis es el mayor desafío al que se enfrenta la Unión en el sentido de responsabilidad y solidaridad, frente a la capacidad de resolver en conjunto un problema que en menor o mayor medida afecta a todos por igual. Frente a este desafío, el proyecto comunitario europeo podría sucumbir si no se aborda la crisis desde el punto de vista de la solidaridad y la cooperación entre los países integrantes, con el objetivo de luchar juntos frente a la pandemia del coronavirus. De todos estos puntos, quizás sea la falta de solidaridad entre los Estados miembros - teniendo en cuenta que esta solidaridad no es una opción, sino que se inscribe en los Tratados de la Unión Europea (art. 2 y 21, TUE; Unión Europea, 1992) - lo que en estos días se encuentra en entredicho. La falta de apoyo financiero de algunos países del norte frente a países del sur presente en la pasada crisis del euro (Sánchez, 2020), se repite en la actual crisis del coronavirus, tal como lo demostró en 2020 la dificultad de llegar a un acuerdo sobre el fondo de recuperación para la pandemia del Covid-19, incluido en el presupuesto 2021-2027 (Cordero, 2020), poniendo en evidencia la inexistencia de una política de integración plena en la UE, tanto a nivel económico - monetario, como epidemiológico - sanitario.

En cuanto a los temas de libre circulación y movilidad en la UE, un antecedente inmediato de la falta de solidaridad entre los países comunitarios lo marca la gestión de la llamada "crisis migratoria" del 2015. Algunas medidas presentadas en este contexto por la Comisión Europea en 2016, como la reubicación de refugiados entre los Estados miembros con poca aceptación en la mayoría de países comunitarios, la reforma del Sistema Común de Asilo (SECA) - del que hasta la fecha no se ha llegado a un acuerdo sobre el sistema de Dublín y el procedimiento de asilo - o la revisión del Código de fronteras Schengen para evitar que se hagan controles injustificados en las fronteras interiores, pusieron de relieve no solamente las tensiones generadas en la búsqueda de acuerdo entre los Estados miembros, sino la falta de solidaridad y responsabilidad de los mismos en la política migratoria común. En este sentido, las desavenencias a largo plazo entre los países integrantes de la Unión hacen reflexionar hasta dónde la soberanía nacional y la falta de solidaridad de los Estados miembros, puede condicionar el modelo de gestión migratoria propuesto en la UE, en el que la política común de inmigración se 
rige por el principio de solidaridad y reparto equitativo de responsabilidades (Art. 80, TFUE; Unión Europea, 2010), también en lo financiero.

En contraste con lo anterior, los aspectos referidos a la seguridad y la lucha contra la inmigración ilegal, basada en el control y expulsión de "migrantes ilegales"2 del territorio comunitario, parecen ser las únicas medidas en la que coinciden los Estados miembros sin mayores discrepancias. Así lo demostró la rápida aceptación de crear una nueva Agencia Europea de la Guardia de Fronteras y Costas en 2016, la aprobación de una mayor financiación para el control de fronteras exteriores y garantía de "retorno eficaz" de migrantes irregulares a sus países de origen y un aumento de presupuesto para el acuerdo de repatriación de refugiados sirios UE-Turquía (10/2015), aprobada en junio de 2018 en la mini cumbre de migración (EUCO 9/18) del Consejo Europeo (2018).

La gestión de la "crisis de los refugiados" ha generado un debate trascendental entre Estados e instituciones de la UE sobre cuál es la política migratoria adecuada y qué responsabilidad tienen los Estados miembros en su ejecución. Teniendo en cuenta que, de acuerdo al marco regulatorio de la Unión, la jurisdicción sobre los solicitantes de asilo y admisión de migrantes en el territorio es competencia nacional de los Estados - que son quienes deciden quién ingresa al país - la toma de decisiones para resolver asuntos migratorios comunes no ha sido una tarea fácil. Esta falta de acuerdo, conjuntamente con la falta de solidaridad de los estados miembros en la política común migratoria, contradice el deseo de acrecentar la solidaridad entre sus pueblos (Preámbulo, TUE; Unión Europea, 1992) señalado en la firma del Tratado de la Unión Europea y nos deja una pregunta a modo de reflexión: ¿Hablamos de "crisis migratoria" o de crisis de integración en la Unión Europea?

Este enfoque de falta de solidaridad de los Estados miembros será el punto de partida de nuestro ensayo, en el que se planteará como interrogante el porqué de la falta de acuerdo en la gestión de la "crisis migratoria" y cómo el aumento de medidas de seguridad, control y retorno forzoso de "migrantes irregulares" en el territorio europeo, ha condicionado la libre circulación de las personas en el Espacio Schengen y reducido

2 La terminología empleada por las instituciones europeas (migrante/es ilegal/es, migrante/s irregular/es) para referirse a las personas migrantes en situación administrativa irregular, será usada siempre que sea posible entre "comillas", en el entendido que dichos términos no son adecuados a las personas, así como tampoco los términos "crisis migratoria" y/o "retorno eficaz" en referencia a las personas migrantes. De igual manera se usará el genérico masculino, sin que ello represente una diferenciación de género. 
los derechos de los inmigrantes en el contexto de la lucha contra la inmigración irregular en la UE.

\subsection{Estructura y metodología}

De acuerdo a sus características, el ensayo se encuadra en la categoría de investigación documental. En el mismo se visualizará analíticamente las medidas propuestas desde el marco institucional de la UE referentes a la gestión de la "crisis migratoria”, el enfoque securitario de la política migratoria europea en el contexto de lucha contra la inmigración irregular y los documentos que dan cuenta del inicio del proyecto integrador europeo y sus resultados.

La estructura del ensayo se divide en dos partes. En la primera "Migración y seguridad en la UE: un debate inacabado", haremos un bosquejo de las principales medidas propuestas por la Comisión Europea en la gestión de la "crisis migratoria" desde el Enfoque Global de la Migración y la Movilidad (COM, 2011) y la Agenda Europea de Migración (Comisión Europea, 2015), con especial énfasis en las acciones llevadas a cabo para aumentar la seguridad en las fronteras exteriores y lograr el "retorno eficaz" de los “migrantes ilegales” a sus países de origen. Destacaremos, además, el enfoque securitario de la política migratoria europea y el combate a la inmigración irregular en el contexto del Espacio de Libertad, Seguridad y Justicia de la UE, señalando aspectos relativos a la reintroducción temporal de controles en el espacio de libre circulación de Schengen, justificados en la seguridad pública y protección de los ciudadanos comunitarios.

En la segunda parte, "Crisis migratoria, soberanía nacional e integración europea" se mencionará a nivel general las medidas llevadas a cabo en el contexto de la "crisis migratoria" de 2015 y de cómo la importancia que los Estados miembros dan a la cuestión de soberanía nacional conduce a una evidente falta de solidaridad y desinterés por llegar a un acuerdo en la política común migratoria. Se señalarán brevemente los antecedentes de integración en el proyecto europeo y las continuas discrepancias que se dan entre los Estados miembros en la resolución de temas comunes. Se enfatizará en cómo la cuestión soberana se ha visto reducida desde el Tratado de Lisboa (2009) con las nuevas competencias compartidas de la UE en el ámbito de las relaciones exteriores y la migración, y de cómo el principio de solidaridad entre Estados miembros - que implica el reparto equitativo de responsabilidades en las cuestiones migratorias - ha ido disminuyendo conforme avanza la autonomía y la falta de integración entre los Estados, lo que ha conducido a la desidia en resolver asuntos de competencia comunitaria. 


\section{Migración y seguridad en la UE: un debate inacabado}

Según datos del Parlamento Europeo (2019), en 2015 llegaron a Europa un millón de migrantes y solicitantes de asilo. Una cantidad de refugiados similar al movimiento de personas que originó la Segunda Guerra Mundial, cuya mayoría venía huyendo del conflicto armado de Siria3, en búsqueda de refugio y protección en la llamada Europa de los Derechos. Esto dio lugar a una respuesta de la UE de más seguridad en las fronteras exteriores e implicación de terceros estados a través de acuerdos de readmisión y cooperación, para controlar y prevenir la entrada de inmigrantes irregulares a la Unión. La Comisión Europea propuso medidas de emergencia para reubicar a los solicitantes de asilo llegados a los países de primera línea y una Agenda Europea de Migración (COM, 2015, 240 final) donde se establecieron medidas para hacer frente a los flujos migratorios irregulares en el territorio europeo. La gestión de la llamada "crisis migratoria” o "crisis de refugiados" estuvo desde el primer momento enfocada a la protección de los ciudadanos que integran el espacio común europeo mediante la lucha contra la inmigración irregular desde el punto de vista del control de acceso en las fronteras exteriores para evitar la entrada de "migrantes irregulares" y la expulsión del llamado "inmigrante ilegal" del territorio comunitario.

\subsection{Categorización de migrantes en la Unión Europea}

Si bien nuestro trabajo no profundiza en la definición y categorización de migrantes, si creemos importante mencionar que parte de la vulnerabilidad y precariedad laboral en la que se encuentran los migrantes en situación administrativa irregular en el suelo comunitario europeo, viene dada por la clasificación como "inmigrante ilegal" desde las instituciones europeas, en el marco de la política migratoria y la lucha contra la inmigración irregular. La expulsión del migrante "sin papeles" del sistema jurídico de derechos laborales y sociales, como bien señala (Zamora, 2017, pp. 306-309), subordina los derechos humanos de las personas a los objetivos políticos, con un consecuente aumento en la criminalización de los inmigrantes y un dispositivo de seguridad cada vez mayor en el marco de la lucha contra la inmigración irregular. Una contradicción en el discurso oficial de las instituciones de la UE, en las que por un lado se habla de un Enfoque Global de la Migración (COM, 2006, 735 final) basado en la integración de los

3 Según ACNUR (dic, 2016) el acogimiento de refugiados en todo el mundo se concentra mayormente en 10 países, solo uno de ellos es europeo: Turquía: 2,9 millones, Paquistán: 1,4 millones, Líbano: 1 millón, Irán: 980 mil, Uganda: 940 mil, Etiopía: 800 mil, Jordania: 685 mil, Alemania: 669 mil, Kenia: 451 mil, Chad: 391 mil. https://eacnur.org/es/actualidad/noticias/emergencias/refugiados-en-el-mundo-un-repaso-encifras-las-ultimas-decadas (Revisado 7, 7, 2021). 
migrantes regulares y cooperación al desarrollo de los países de origen, y por el otro de forma paralela se habla de una política migratoria basada en la prevención de entrada, control y expulsión de los "migrantes irregulares" del territorio comunitario. Pertenecer al sector caracterizado por la negación de derechos, la persecución, la exclusión, el encierro y por último la expulsión, es consecuencia de la condición de "inmigrante ilegal”, definida desde la generalidad por el estatus legal en el que se encuentra el migrante y no desde la individualidad que le otorga el hecho de ser persona en una determinada sociedad. En el informe del Alto Comisionado de las Naciones Unidas para los Derechos Humanos (ACNUDH, 2013: 23) se recomendaba a las instituciones de la UE, específicamente al Consejo de Ministros la no utilización del término "migrante ilegal”, sustituyéndolo a su vez por el de "migrante irregular". Si bien esta medida es certera, ya que desde el punto de vista de la legalidad no existen personas sino acciones ilegales, la variación del significado, lamentablemente, no ha cambiado el discurso político europeo en el que se continúa con la criminalización de los migrantes en situación administrativa irregular en el terreno comunitario.

De igual manera, la ciudadanía de la UE (Directiva 2004/38) - ciudadano comunitario - en el marco de la integración europea, designa automáticamente "extracomunitario" a todos aquellos extranjeros que no poseen nacionalidad de alguno de los países integrantes de la Unión. Esta distinción entre ciudadanos europeos y ciudadanos extracomunitarios, enmarcado en la lucha contra la inmigración ilegal, tiene sus orígenes en la misma creación del TUE (Unión Europea, 1992, Título VI, Art K1.3) donde se menciona el tratamiento de la inmigración clandestina como asuntos de interés para todos los Estados miembros. A este respecto, la terminología, "nacionales de terceros países" diferentes a la UE, se consolida pocos años después en el Consejo Europeo de Tampere (1999), cuando se distingue entre inmigrantes legales e inmigrantes ilegales, en el marco de lucha contra la inmigración ilegal. Aunque en líneas generales ser extracomunitario o nacional de un país no perteneciente a la UE (terceros países) vendría a significar lo mismo, lo cierto es que en la práctica ser ciudadano suizo extracomunitario, no es lo mismo que ser ciudadano senegalés extracomunitario, tanto en el acceso como en la permanencia dentro del territorio comunitario. Se podría argumentar que Suiza integra el Espacio Schengen a diferencia de Senegal, si bien en el caso que nos ocupa, sabemos que la disparidad está dada por otros factores que no procede analizar en este trabajo. Desde la definición de categorías de migrantes a la admisión y/o negación de entrada al territorio europeo, la gestión de la política migratoria de la UE se basa fundamentalmente en medidas de control y prevención de ingreso de "migrantes irregulares", condiciones de permanencia en el territorio europeo 
y expulsión de aquellos que se encuentren residiendo ilegalmente o no cumplan con las condiciones en la solicitud de asilo para obtener el estatuto de refugiado. Una política migratoria altamente restrictiva de enfoque securitario, que, desde su estructura institucional y ejecución de normas, prioriza la vigilancia policial y la lucha contra la inmigración ilegal a la integración de migrantes y derechos de las personas (ACNUDH, $2013: 12)$.

\subsection{El retorno eficaz y la reducción de incentivos a la inmigración ilegal.}

Uno de los tópicos que más abundan en el discurso de la UE es la prioridad en su política migratoria de reducir los incentivos a la inmigración irregular, entendido éste por mejorar la eficacia de las políticas de retorno para que se conviertan en "retorno eficaz" de los "migrantes ilegales" a sus países de origen, desmantelar las redes de tráfico y trata de personas y trabajar con los países socios para conocer las causas por la que los migrantes deciden venir a Europa. Reducir los incentivos a la inmigración irregular, es el primero de los cuatro pilares que se presentan en la Agenda Europea de Migración (COM, 2015, 240 final, p. 9) en el que se incluye el "retorno eficaz" de migrantes, como forma de mejorar la gestión de la migración en la UE. La Agenda destaca que uno de los incentivos a la migración irregular es la certeza de que el retorno de migrantes funciona de forma imperfecta, ya que solo se expulsa a un 32\% (Ídem, 2015, p. 11) de las decisiones de retorno emitidas. Es por ello que la Comisión Europea propone a partir de la "crisis migratoria" de 2015 una serie de recomendaciones para realizar eficazmente el retorno de migrantes. Así pues, en marzo de 2017, la Comisión Europea presenta un Plan de Acción Renovado (COM, 2017, 200 final) para una política de retorno eficaz en la Unión, conjuntamente con una actualización del Manual de Retorno, en septiembre del mismo año. Estas recomendaciones de "retorno eficaz" que alientan a los países de la UE a incrementar la expulsión de inmigrantes como medida para eliminar los incentivos a la inmigración ilegal, derivan de la correcta aplicación de la Directiva de Retorno (2008/115/CE), llamada también la "directiva de la vergüenza" por las acciones planteadas en cuanto al encierro y las deportaciones de inmigrantes. Siguiendo con la estrategia de retorno y expulsión de nacionales de terceros países que residen ilegalmente en la UE, en 2018 las conclusiones de la cumbre de migración del Consejo Europeo (2018, EUCO 9/18) destacan el aumento de retorno de "migrantes irregulares" y el control efectivo en las fronteras exteriores, junto a una mayor acción exterior en materia migratoria, como objetivo a cumplir en la reducción de la migración ilegal en la UE. 


\subsection{Prevenir la entrada y facilitar la salida.}

En la práctica, se ha comprobado que expulsar una persona del territorio europeo, no siempre es fácil, ya que es necesario la cooperación de los países de origen de los retornados. Debe existir un previo acuerdo de repatriación firmado entre la UE y el país de origen o tránsito del expulsado y estos acuerdos no siempre existen, por lo que es más fácil impedir la entrada de una persona que expulsarla luego de que esté residiendo en la UE. En este sentido, a partir de la "crisis migratoria" de 2015 el refuerzo en la seguridad de las fronteras exteriores ha estado acompañado de la dimensión exterior de la política migratoria y el aumento de acuerdos de cooperación y readmisión de migrantes (Parlamento Europeo, 2020/2116.INI) con países de origen y/o tránsito de migrantes, para prevenir las entradas irregulares y facilitar la expulsión de migrantes en situación administrativa ilegal en la UE. Estos acuerdos con terceros países están orientados a prevenir la entrada de migrantes irregulares y realizar un "retorno eficaz" de aquellos que no residan legalmente en el territorio. La dimensión exterior de la política migratoria se basa fundamentalmente en el Enfoque Global de la Migración y la Movilidad (COM, 2006, 735 final y COM, 2011, 743 final) que establece un marco general de relaciones de la UE con terceros países, basado en cuatro pilares: inmigración legal y movilidad, inmigración irregular y trata de seres humanos, protección internacional y política de asilo. Una perspectiva global de la migración, que está orientada casi de forma exclusiva a controlar las fronteras para evitar las entradas irregulares y deportar a las personas que se encuentran residiendo en situación administrativa irregular dentro del suelo comunitario europeo. Esta dimensión externa de la política migratoria a través de los acuerdos de readmisión de migrantes y colaboración estrecha con países de origen y tránsito de personas migrantes, se intensifica desde el Programa Estocolmo (Consejo Europeo, 2010, 2010/C 115/01, p. 31) como medida fundamental de lucha contra la inmigración ilegal en el marco del enfoque global en el que se gestiona la política migratoria. Al respecto, Zapater Duque (2010, p. 20), señala que la dimensión externa a través de los acuerdos de readmisión puede afectar a aquellas personas de terceros países con las que la UE tiene una responsabilidad, desde el punto de vista de los derechos humanos y cuestiones de asilo.

Este enfoque restrictivo de la cuestión migratoria orientado a la prevención de entradas y retorno de migrantes en situación administrativa irregular en la UE ha dado lugar a un amplio despliegue de medidas de seguridad y control en las fronteras exteriores de la Unión. La incorporación en el último lustro de un sistema de "fronteras inteligentes" (Parlamento Europeo, 2018, p. 14) con modernos sistemas tecnológicos para identificar a las personas que ingresan al suelo comunitario a través de las huellas 
dactilares, datos biométricos (Eurodac), conjuntamente con el refuerzo de los controles mediante la revisión del Código de Fronteras Schengen (Reglamento (UE) 2016/399), la transformación de Frontex a la nueva Agencia Europea de la Guardia de Fronteras y Costas (Reglamento (UE) 2016/1624), la creación de un Sistema Europeo de Información y Autorización de Viajes (COM, 2016, 731 final) y el establecimiento en 2015 de Hotspots (COM, 2015, 679 final) "puntos críticos” en países de primera línea (Italia y Grecia) para facilitar la identificación y/o posible retorno de migrantes, son una prueba de la rigidez y aumento de la seguridad en la gestión de las fronteras externas, como medida prioritaria en la lucha contra la inmigración ilegal. En relación con lo anterior y sumadas a todas las medidas de control y seguridad para evitar el cruce ilegal de las fronteras exteriores, existen medidas de décadas anteriores, enfocadas a la prevención de entrada de "migrantes irregulares" al territorio, como la Directiva (2002/90/CE) o la Decisión marco (2002/946/JAI) sobre definición y penalización de ayuda a la entrada, circulación y/o estancias irregulares en el territorio europeo. Del mismo modo, en lo referente a la política migratoria la Agenda Estratégica (2019-2024) de la UE (Consejo Europeo, 2019), hace hincapié en el control de fronteras, la restricción de entradas de inmigrantes, el aumento de retornos y los acuerdos de readmisión con terceros países, como forma de combatir la migración irregular y garantizar la seguridad e integridad del territorio europeo.

\subsection{Trabajadores "ilegales" en la Unión Europea.}

El derecho al trabajo, a trabajar y/o buscar trabajo, es inherente a todo ser humano. Sin embargo, esta libertad plasmada en la Carta de los Derechos Fundamentales de la UE (2012/C 326/o2. Art. 15, apartado 1)4, se concede según el Artículo 15 apartado 2 y 3 (Ídem) únicamente a los ciudadanos comunitarios y a aquellos ciudadanos de terceros países autorizados a trabajar en el suelo comunitario, para quienes se otorgará condiciones laborales equivalentes a los nacionales (Fonseca, 2001:83). En este sentido la Comisión Europea prohíbe el empleo a nacionales de terceros países sin derecho a residir en la UE (Agenda Europea de Migración; Comisión Europea, 2015, p. 11), aplicando sanciones a los empleadores (Directiva 2009/52/CE) que contraten "inmigrantes irregulares", como forma de luchar contra el trabajo ilegal. Para aquellos trabajadores que a priori se encuentran en situación administrativa ilegal en el suelo comunitario, no hay demasiadas opciones. La regulación de los inmigrantes - esto es

4 La Carta de los Derechos Fundamentales de la Unión Europea (2000) tiene la misma validez jurídica que los Tratados de la UE (Artículo 6, apartado 1, del TUE), si bien no ha sido incorporada al TFUE (2009). 
conceder el estatus de legalidad a aquellos migrantes extracomunitarios que residan en el territorio de forma ilegal - no está prevista en la política migratoria europea, quedando en el ámbito de la jurisdicción nacional la aceptación y volumen de migrantes en búsqueda de trabajo (Programa de la Haya, 2005/C 53/p. 01-4), si bien es la UE quién establece las condiciones para obtener el permiso único de residencia y trabajo (Directiva 2011/98/UE). En la Agenda Europea de Migración se menciona que quiénes “[(...) viven en la clandestinidad en Europa llevan una existencia precaria y pueden convertirse fácilmente en víctimas de la explotación (...)]" (Comisión Europea, 2015, p. 9). No se profundiza a qué tipo de explotación se refiere y se ofrece como única solución a esta explotación, la aplicación eficaz de la Directiva de Retorno (2008) relativa a las normas y procedimientos comunes en los Estados miembros para la deportación de migrantes en situación irregular. Se acepta la fuerza física, pero se rechaza la legalidad, y con ello la posibilidad de que trabajadores y trabajadoras migrantes sean plausibles de tener derechos. Una política de inmigración que reduce los derechos de las personas en beneficio del mercado y la economía capitalista (De Lucas, 2002), con una posición compartida de la Comisión Europea con los Estados miembros, de la migración desde el punto de vista de la utilidad y el recaudo económico, dónde la única migración laboral que se promueve es la de trabajadores altamente cualificados (Gsir, 2013, p. 110).

\subsection{El espacio de libertad, seguridad y justicia como emblema de la política migratoria}

Desde la firma del Tratado de Maastricht (TUE; Unión Europea, 1992), la migración en el territorio europeo ha sido considerada un problema de seguridad y política exterior, enfocado a la lucha contra la inmigración irregular, siendo en este contexto y no en el de integración de los migrantes, dónde se diseñan la mayoría de las políticas del entorno migratorio. El Tratado se consolidó resuelto a garantizar la seguridad y protección de sus pueblos (TUE, Preámbulo), al mismo que tiempo que facilitaría un espacio de libre circulación de las personas. De forma conjunta a esta determinación, se inscribieron las bases para una política migratoria que garantizara la seguridad de los ciudadanos europeos mediante el control de las fronteras exteriores y la lucha contra la inmigración irregular y la delincuencia. El diálogo entre instituciones de la UE y los Estados miembros referente a la gestión de los flujos migratorios de ciudadanos extracomunitarios que llegan al suelo comunitario europeo ha estado desde el comienzo mismo del proyecto integrador europeo, enfocado a la seguridad de sus ciudadanos. Es así que, la frase tan citada en el entorno de la institucionalidad europea de "lucha contra la inmigración irregular", comienza a mencionarse con mayor frecuencia a partir de 
1999, con la entrada en vigor del Tratado de Ámsterdam 5 y el desarrollo de la política exterior y refuerzo de cooperación intergubernamental en el ámbito policial, penal y judicial, debido a la incorporación del acervo de Schengen al derecho de la UE.

En base a las disposiciones de este Tratado, es que más adelante en el Programa de Tampere (Consejo Europeo, 1999), se destaca la importancia de hacer realidad el espacio de libertad, seguridad y justicia y el establecimiento de una política común a los Estados miembros en el ámbito del asilo, la inmigración y el cruce de fronteras exteriores asociado a este espacio. De igual manera, la importancia de luchar contra la inmigración clandestina en los territorios comunitarios se ve reforzada en el Tratado de La Haya (Consejo Europeo, 2005) dónde se destaca la necesidad de fortalecer el espacio de libertad, seguridad y justicia de la Unión, con un mejor sistema de seguridad para la UE y sus Estados miembros luego de los atentados terroristas en EE. UU. (2001) y España (2004). Se señala, además, la urgencia de solventar los problemas transfronterizos como la migración ilegal, trata de personas, delincuencia organizada y terrorismo entre otros, así como la necesidad de instaurar políticas de integración de la migración legal y políticas de lucha contra el trabajo ilegal, políticas de retorno, repatriación y readmisión de inmigrantes ilegales. En este sentido, Gemma Pinyol (2018, p. 74-82) señala que el tratamiento en paralelo y fragmentado de la normativa migratoria, dónde por un lado se diseña políticas públicas de integración para la migración legal y por otro se ejecutan políticas de seguridad y retorno para la inmigración ilegal, subordina el desarrollo de vías de migración legal frente al desarrollo de políticas de control de fronteras, distorsionando de esta manera una política integrada de inmigración y asilo.

El Programa de Tampere (Consejo Europeo, 1999) marcó el inicio de las que serían luego las disposiciones generales del actual Título V del TFUE el Espacio de Libertad, Seguridad y Justicia (ELSJ) acordado en Lisboa en $2007^{6}$, cimentado en el TUE (Art. 3) y los preceptos del Tratado de Ámsterdam (1997) y Consejo de Tempere (1999-2004). La definición del ELSJ en el Tratado de Lisboa, conjuntamente con la regulación de las políticas inherentes al control de fronteras, asilo e inmigración y el reparto equitativo de responsabilidad de los Estados miembros, se basa en el principio de solidaridad (Art. 79 y 80, TFUE; Unión Europea, 2010), siendo asimismo en el Tratado de Lisboa, donde se estructura la necesidad de desarrollar una política de inmigración común a los Estados

5 El Tratado de Ámsterdam, por el que se modifican el Tratado de la Unión Europea (TUE), los Tratados constitutivos de las Comunidades Europeas y determinados actos conexos se firmó en Ámsterdam el 2 de octubre de 1997 y entró en vigor el 1 de mayo de 1999.

6 Tratado de Lisboa por el que se modifican el Tratado de la Unión Europea y el Tratado constitutivo de la Comunidad Europea a (DO C 306 de 17.12.2007) entró en vigor en diciembre de 2009. 
que integran la UE y el requerimiento de la solidaridad de los Estados miembros, para que ésta sea exitosa. De ahí que, en el ámbito de los Tratados de la UE la política común referente a inmigración, asilo, visado y controles de fronteras se fundamente en el Título V del Tratado de Lisboa (TFUE, 2009), sobre el Espacio de Libertad, Seguridad y Justicia, en el suelo comunitario. Este avance en la cooperación intergubernamental desde el Tratado de Ámsterdam se ha visto mayormente reflejado en los ámbitos de cooperación judicial en materia penal y policial, siendo a partir del TFUE cuando los temas de inmigración y asilo en la UE se consolidan como asuntos de seguridad interior de los Estados, bajo el carácter común del espacio de libertad, seguridad y justicia, en el que se gestionan los flujos migratorios (Goig Martínez, 2017, p. 95). Una cooperación intrafronteriza que (en teoría) se basa en el ejercicio de la solidaridad de los Estados miembros y la búsqueda de una política común de asilo e inmigración, junto a un sistema integrado de control de las fronteras exteriores, respetando el principio de subsidiariedad y proporcionalidad desde las instituciones de la Unión (TFUE, Art. 67, TUE, Art. 5; Unión Europea, 1992).

\subsection{El Espacio Schengen y el control de las fronteras exteriores de la UE.}

El actual espacio de libre circulación y cooperación entre Estados miembros relativos a Schengen, se basan en la firma del Tratado Schengen en 1985 (entrada en vigor en 1995) y la integración del mismo al Derecho de la Unión Europea en el Tratado de Ámsterdam en 1997. La libre circulación de personas se acompañó de medidas compensatorias como el Servicio de Información Schengen (SIS), para mejorar la cooperación y coordinación entre servicios policiales y judiciales en aras de proteger la seguridad interior de los Estados miembros. Este antecedente de libre circulación y residencia de las personas dentro de la UE, iniciado con Schengen, marcó uno de los preceptos básicos del proceso de construcción europea, aunque no fue hasta el Programa de Tempere (1999) que se planteó la necesidad de fundamentar una política migratoria común entre Estados que implicara la protección de las fronteras exteriores, como fundamento al espacio de libre circulación. En palabras de Pinyol (2018), ha sido este desajuste temporal el que ha marcado las dificultades posteriores para entender que, en relación al espacio de libertad, seguridad y justicia, la política de inmigración y asilo común es un requisito imprescindible y no optativo entre los Estados que integran la Unión Europea.

Una política migratoria orientada desde el comienzo a la protección de sus ciudadanos en un entorno de libertad de movimiento y seguridad en el territorio europeo, siendo el refuerzo en el control de las fronteras exteriores, la justificación a la 
permanencia y garantía del acervo Schengen. Es así, que en el marco de la llamada "crisis migratoria” y las nuevas medidas de la Comisión Europea para frenar las llegadas de irregulares y evitar desplazamientos secundarios de refugiados y migrantes en los territorios de la Unión, se propone en 2016 la creación de la nueva Agencia Europea de la Guardia de Fronteras y Costas, para ayudar a Estados miembros y países asociados a Schengen en el control de las fronteras exteriores y protección del espacio de libre circulación. El objetivo de la creación de la nueva Agencia es ampliar las competencias de Frontex (creado en 2004) en la gestión integrada de fronteras, pasando entre otros aspectos, a coordinar de forma conjunta con los Estados miembros las operaciones de retorno forzado de migrantes. Los temas migratorios en la UE se baten en el plano de ofrecer protección a sus ciudadanos en un entorno de libertad de movimiento y seguridad en el territorio europeo, siendo uno de los principales argumentos en defensa de la política migratoria común de Estados e instituciones europeas la defensa de la población autóctona, fundamentada en la otredad europea (Friese, 2005) y la lucha permanente contra esos "extraños llamando a la puerta" (Bauman, 2016), para los que no hay espacio en el suelo europeo.

Las fronteras exteriores, según el discurso europeo, deben extremar la seguridad y el control para prevenir la entrada de cualquier amenaza al orden público en el espacio comunitario interior, asegurando al mismo tiempo la permanencia del Espacio Schengen y la ausencia de controles en las fronteras internas. Sin embargo, los controles fronterizos internos ya han sido ejercidos en la UE. El aumento de llegadas de migrantes y solicitantes de asilo al territorio europeo en 2015, fue considerado un problema preocupante de seguridad, con el que varios Estados miembros (COM, 2016, 120 final) justificaron el control fronterizo en la supuesta amenaza que representaba para la seguridad interior, el desplazamiento interno de los migrantes en la Unión. Esto afectó por mucho tiempo el normal funcionamiento del espacio de libre circulación y quebrantó normas del Código de fronteras de Schengen, que señala que el solo hecho de cruzar las fronteras no es motivo para introducir temporalmente controles fronterizos internos, ya que estos solo deben hacerse con carácter excepcional y por razones de grave amenaza a la seguridad (Apartado 21. (UE) 2016/399). Esta trasgresión del espacio de libre circulación de Schengen llevó a la elaboración de una propuesta legislativa por la Comisión Europea (COM, 2017, 570), para garantizar que dichos controles sigan siendo una medida de último recurso con la mínima duración posible para responder a la amenaza. En la misma, no solamente se especifica que los controles internos de fronteras se realizarán únicamente en circunstancias excepcionales que afecten al orden público o la seguridad del espacio comunitario, sino que se da cuenta del costo económico que 
generan estos controles en la economía de la Unión. Es importante aclarar aquí que, en el contexto de la actual crisis sanitaria generada por la pandemia del Covid-19, se ha establecido el cierre de las fronteras externas e internas de la UE, incluyendo controles fronterizos a la movilidad y restricción temporal de viajes en el Espacio Schengen (COM, 2020, 115 final), lo que afecta a todos los ciudadanos de la Unión, no solo a los ciudadanos extracomunitarios.

Garantizar a largo plazo el espacio de libre circulación del acervo Schengen ha sido uno de los puntos fuertes del debate que originó la llegada de refugiados al territorio europeo. Un debate que sigue hasta el presente y pone en duda la libre circulación de personas en la UE, así como la responsabilidad de los Estados miembros en resolver asuntos de competencia comunitaria como lo es la política migratoria. En este sentido algunos autores como (Mavrouli, 2019, p. 113), señalan que las fronteras internas de la UE se han vuelto fronteras externas, debido a la vigilancia instaurada para salvaguardar la seguridad de los ciudadanos del territorio europeo, en detrimento de la libertad de circulación en Schengen y la protección de los migrantes. De igual manera la securitización de los temas migratorios enfocado al orden público en la UE con un reclamo permanente de "seguridad nacional" en los Estados miembros, junto al enfoque securitario de la política migratoria europea para prevenir la inmigración irregular, conducen a una pérdida de libertad y derechos fundamentales de las personas migrantes (Goig Martínez, 2017, p. 97).

\section{Crisis migratoria, soberanía nacional e integración europea}

Las primeras medidas que se llevaron a cabo desde las instituciones europeas, luego de la llegada de un amplio número de migrantes y refugiados a la Unión Europea en 2015, estuvieron enfocadas a ordenar los flujos migratorios y contener la migración irregular. En este contexto se crea la nueva Agencia Europea de la Guardia de Fronteras y Costas (ya mencionada) para reforzar Frontex y el Plan de Acción Conjunto UE-Turquía (COM, 2016, 144 final), un acuerdo de refuerzo en los controles fronterizos turcos para evitar la salida de migrantes desde su territorio a la UE y compromiso de readmitir a los refugiados sirios y/o migrantes llegados irregularmente a Grecia desde Turquía. Además, en el marco de la gestión de la "crisis de refugiados", la Comisión Europea plantea medidas de aplicación inmediata, entre las que destaca el mecanismo de reubicación de emergencia para aliviar a los países de primera línea (Grecia e Italia) que recibieron mayor número de migrantes (UE) 2015/1601), y la propuesta en 2016 para reformar el SECA (COM, 2016, 197 final y COM, 2016, 270 final), que incluye siete propuestas 
legislativas conectadas entre sí sobre las condiciones de acogida, requisitos de asilo, agencia de asilo, base de datos biométricos y refuerzo de Eurodac (UE) 2019/818), sistema de Dublín y procedimiento de asilo. La respuesta de los Estados miembros a estas medidas fue acatada de forma desigual. Aprobándose sin recelos aquellas medidas que requerían de un aumento de presupuesto para reforzar la seguridad y frenar las llegadas de migrantes a la UE y dejando en lista de larga espera la reubicación de refugiados, la reforma del SECA y la conservación del espacio de libre circulación de Schengen.

Un ejemplo de ello es el acuerdo UE-Turquía (2015), financiado inicialmente con 3000 millones de euros con presupuesto de la UE y los Estados miembros, admitido rápidamente, con el incremento de una segunda partida adicional de 3000 millones de euros en 2018 (EUCO/2018 y COM, 2016, 85 final). Este acuerdo convirtió a las personas migrantes y refugiados geopolíticamente en moneda de cambio a través de un acuerdo de retención y admisión de personas deportadas a cambio de dinero (Sanahuja, 2016, p. 72) y demostró el incumplimiento por parte de la UE de la Convención sobre el Estatuto de los Refugiados (1951) al plantear en el acuerdo una medida de "devolución en caliente" de los migrantes en el que se violan los derechos de asistencia y protección de los refugiados (Núñez Villaverde, 2016). De igual manera la creación de la nueva Agencia Europea de la Guardia de Fronteras y Costas para incrementar la seguridad en las fronteras exteriores y acelerar los procesos de expulsión de migrantes en situación irregular en la UE, fue velozmente aprobada.

Referente al mecanismo de reubicación de emergencia de refugiados entre los Estados miembros, la decisión se valoró con un cupo de reubicación estimado según el umbral de la tasa media de cada país integrante respecto a la UE, para garantizar que las personas necesitadas de protección internacional pudieran disfrutar de sus derechos en el país donde fueran reasentados (UE) 2015/1601). Sin embargo, no todos los Estados miembros cumplieron en acoger la cantidad de migrantes fijado por la UE y otros como el caso de Polonia, Hungría y República Checa, se negaron a acoger refugiados, lo que les costó un procedimiento de infracción de parte de la Comisión Europea (Mavrouli, 2019, p. 90). La obligación de los Estados miembros de acoger las cuotas de refugiados designadas por la UE está relacionado al principio de solidaridad y reparto equitativo de la responsabilidad en el marco de las políticas sobre controles de las fronteras, asilo e inmigración (Art. 80 del TFUE; Unión Europea, 2010). En este sentido, la posición autónoma de algunos Estados miembros de no acoger el número de refugiados otorgados no solamente contrasta con los supuestos valores de responsabilidad y solidaridad entre Estados, sino que incumple disposiciones fundamentales en la que se basa la política 
común migratoria. De igual manera, la reforma del SECA sigue luego de un lustro, esperando a que los Estados miembros se pongan de acuerdo y aprueben un nuevo sistema para distribuir mejor las solicitudes de asilo entre los Estados miembros y la sustitución de la Directiva sobre procedimientos de asilo por un Reglamento común de protección internacional dentro de la UE. Asimismo, las medidas que algunos Estados miembros llevaron a cabo en defensa de la seguridad pública y amenaza a sus territorios, reintroduciendo los controles fronterizos, cuestiona la viabilidad del espacio de libre circulación dentro del acervo Schengen. Esta medida ejecutada para evitar movimientos secundarios de migrantes y refugiados en el territorio comunitario, demuestra la prioridad soberana frente a lo comunitario. Un debate que sigue hasta el presente y que pone en duda la libre circulación de personas en el Espacio Schengen, así como la responsabilidad de los países miembros de la UE en resolver asuntos de competencia comunitaria, junto al ejercicio de solidaridad entre Estados, para resolver un tema de objetivo común como lo es la política migratoria europea.

Bajo esta óptica, podría decirse que la gestión de la llamada "crisis migratoria" o "crisis de refugiados" ha demostrado a través del tiempo la falta de responsabilidad y solidaridad de los Estados miembros en cumplir con la cuota de reubicación de refugiados y llegar a un acuerdo para mejorar la distribución de las solicitudes de asilo (Sistema Dublín), conjuntamente con un procedimiento de asilo común a todos los Estados. Una falta de interés en resolver asuntos comunes de la política migratoria que afecta en primer lugar a las personas migrantes, y demuestra a su vez la crisis de integración y de gobernanza en la UE (Sanahuja, 2016, p. 72) que ha estado presente desde el mismo inicio del proyecto integrador europeo.

\subsection{Antecedentes de integración en el proyecto europeo}

La integración europea desde los inicios de los Tratados de Roma (1957) ha estado marcada por un relativo rápido consenso entre los Estados miembros, respecto a intereses comerciales y monetarios. De este entendimiento nace la Comunidad Económica Europea (CEE), el proyecto "Europa verde" y los primeros reglamentos para la Política Agrícola Común (PAC) y el Fondo Europeo de Orientación y de Garantía Agrícola en 1962. Sin embargo, en el campo de la integración política los Estados miembros no han sido tan "veloces" en la toma de decisiones. El primer antecedente al respecto data del año 1954, con el proyecto fallido de la Comunidad Europea de Defensa, seguido por las tentativas en 1962 de la comisión intergubernamental presidida por el francés Christian Fouchet y su fracasado intento de presentar a los Estados miembros un proyecto de unidad política respetando la identidad de los países integrantes. Estos años 
se caracterizan por períodos políticos de "desacuerdos comunes" como lo fue la crisis política de la "silla vacía" en 19667. Crisis provocada por el cambio de modalidad de votación en el Consejo en el que se sustituye la unanimidad por la mayoría cualificada en ciertos ámbitos, convergiendo en el abandono de Francia de las reuniones comunitarias, debido al desacuerdo sobre las propuestas de financiación de las PAC. Es así que, ante la inexistencia de una unificación política entre Estados miembros, se apela a la llamada “Cooperación Política Europea en 1970, ampliada unos años más tarde en la que sería el Acta Única Europea (1986).

El Acta que entró en vigor en 1987, modificó el Tratado de Roma y dispuso la ampliación de las competencias de la Unión mediante la creación de un Mercado Interior y el reconocimiento de nuevas competencias en el terreno de la política monetaria, cohesión económica, social, medio ambiente y de cooperación política exterior ${ }^{8}$. En estos años además, se concretó uno de los mayores triunfos de integración entre Estados en el proceso de construcción europea, como es el derecho de libre circulación y residencia de las personas dentro de la UE, iniciado en 1985 con el Tratado Schengen. La creación de este espacio de libre circulación que conforma uno de los pilares del proyecto europeo, fue en principio firmado por Francia, Alemania, Bélgica, Luxemburgo y los Países Bajos, y estuvo acompañado de un debate en relación al concepto d libre circulación de personas, entre aquellos Estados que coincidían en la aplicación solo para ciudadanos del territorio europeo - lo que implicaba el control de fronteras interiores - y aquellos que abogaban por la libre circulación de personas y la supresión total de fronteras en Schengen. ${ }^{9}$ El acuerdo Schengen entró en vigor en 1995 y fue integrado al Derecho de la Unión Europea en el Tratado de Ámsterdam en 1997.

Llegamos así a 1999, donde las conclusiones de la Presidencia del Consejo Europeo de Tampere daban cuenta de los logros conseguidos en el mercado único, la unión monetaria y la capacidad para asumir retos políticos, hasta el momento en el espacio compartido de la Unión, señalando la importancia de la creación de un sistema europeo común de asilo mediante el trabajo conjunto de los Estados miembros. Un sistema común de asilo que debería incluir normas comunes a todos los Estados sobre el

\footnotetext{
7 Fichas técnicas de la Unión Europea. La Evolución hacia el Acta Única Europea. Recuperado de: https://www.europarl.europa.eu/factsheets/es/sheet/2/la-evolucion-hacia-el-acta-unica-europea 8 Ídem.

9 Países de la Unión Europea como Bulgaria, Croacia, Chipre o Rumanía, aún no integran el acervo Schengen por no reunir las condiciones, así como hay países que cooperan en la libre circulación de Schengen que no pertenecen a la Unión Europea: Islandia, Liechtenstein, Noruega y Suiza https://ec.europa.eu/homeaffairs/sites/homeaffairs/files/e library/docs/schengen_brochure/schengen_brochure_dr3111126_es.pdf
} 
procedimiento de acogida de los solicitantes de asilo, así como formas comunes de protección subsidiaria a toda persona que lo necesite y un enfoque global de la migración orientada a los derechos humanos y desarrollo de los países de origen y tránsito de los migrantes (Tampere, Consejo Europeo, 1999, p. 4).

Más adelante, en el Programa de La Haya (2005/C 53/01) se señalaba la continuidad de esta política común basada en la solidaridad y reparto equitativo de responsabilidades entre los Estados miembros, a fin de instaurar un procedimiento común de asilo en la UE. Se llega así a las disposiciones comunes de colaboración estrecha entre los Estados miembros señaladas en el Capítulo 2 del Tratado de Lisboa, sobre el control de fronteras, asilo e inmigración (TFUE, 2007, art. 79 y 80; Unión Europea, 2010) en el marco de una política común migratoria. Un año después de la entrada en vigor del TFUE (2009) en el apartado 6.1 del Programa de Estocolmo (2010/C 115/o1) se reitera la necesidad de que la política de migración forme parte de la política exterior de la UE en el marco del enfoque global de la migración y cooperación de terceros países en la lucha contra la inmigración irregular. Comienza así el desarrollo de los acuerdos de readmisión y cooperación con terceros países (COM, 2011, 76 final) en el ámbito de la lucha contra la inmigración irregular y la protección de los ciudadanos comunitarios en el espacio de libertad, seguridad y justicia de la UE.

\subsection{La dificil tarea de ponerse de acuerdo}

Resumiendo lo expuesto anteriormente, podemos decir que el control de fronteras y la gestión de los flujos migratorios en la UE, en el marco del espacio de libertad, seguridad y justicia es un compromiso conjunto de los Estados miembros y las instituciones de la UE, basado en el principio de solidaridad entre Estados y el reparto equitativo de responsabilidad, también concerniente a lo financiero (Art. 80, TFUE; Unión Europea, 2010). Tanto la cuestión migratoria como la acción exterior son ámbitos de actuación propios de la soberanía nacional de los Estados, lo que hace que se planteen controversias, a raíz de la determinación de competencia compartida en el espacio de libertad, seguridad y justicia (TFUE. Art. 4, Apartado 2. Letra J) y la lucha contra la inmigración irregular a partir de la entrada en vigor del Tratado de Lisboa (2009). La trasferencia voluntaria de soberanía desde los Estados miembros a las instituciones europeas, con el objetivo de perseguir intereses comunes en el terreno de la política migratoria, no es un asunto de fácil de digerir, provocando muchas veces el retraso en la aprobación de medidas en el ámbito migratorio. Una cuestión de soberanía nacional de los Estados, que se ha visto disminuida desde el Tratado de Lisboa en la que los actos jurídicos relativos al espacio de libertad, seguridad y justicia dejan de tener carácter 
intergubernamental y pasan al procedimiento legislativo ordinario de mayoría cualificada y codecisión. Esta modificación en la toma de decisiones confiere nuevas competencias compartidas a la Unión, entre las que se destaca el ámbito de relaciones exteriores y migración ${ }^{10}$. Es además en este Tratado donde se otorga personalidad jurídica a la UE, que queda facultada para firmar acuerdos internacionales en los ámbitos de competencia compartida, como es el migratorio.

Aun cuando el Tratado de Ámsterdam había otorgado competencias a la Comunidad Europea en temas referidos al control de fronteras e inmigración irregular, nunca hasta la entrada en vigor del Tratado de Lisboa, la UE había tenido la competencia expresa para desarrollar una acción de política exterior como la firma de acuerdos de readmisión con terceros países en materia migratoria (García Andrade, 2015, p. 98), incluyendo la expulsión y repatriación de personas en situación administrativa irregular. En este sentido, tanto las relaciones exteriores y las migraciones, ambos estrechamente vinculados a la soberanía de los Estados, se han visto condicionadas por la transferencia voluntaria del ejercicio del poder desde los Estados a las instituciones europeas (García Andrade, 2015, p. 32). Si bien desde el comienzo del proyecto de integración de la UE cuando aún era Comunidad Europea - los Estados miembros le han concedido a las instituciones de la Unión, la potestad de relacionarse con otros sujetos del Derecho Internacional en determinadas esferas políticas, la cesión de poderes no ha sido una tarea fácil, tal como lo demuestran las competencias compartidas en el marco institucional de la política migratoria y la acción exterior en los tratados constitutivos de la UE (García Andrade, 2015, p. 32). Una política exterior común que se volvió necesaria desde el establecimiento del espacio de libertad, seguridad y justicia y la gestión de fronteras exteriores comunitarias por parte de los Estados miembros, ante la ausencia de controles fronterizos en el espacio interior europeo.

\section{Reflexiones finales}

La gestión de la política migratoria de la UE está enfocada al control de las fronteras exteriores para prevenir la entrada de migrantes irregulares, condiciones de permanencia en el territorio europeo y expulsión de aquellos que se encuentren residiendo ilegalmente o no cumplan con las condiciones en la solicitud de asilo para

10 En el Tratado de Lisboa por primera vez se clasifican las competencias de la UE: exclusiva (solo la UE puede legislar), compartida (ambos, UE y Estados miembros pueden legislar) y de apoyo (aquellas en las que la UE toma medidas para apoyar o complementar políticas de los Estados Miembros). Tratado de Lisboa. Recuperado de: https://www.europarl.europa.eu/factsheets/es/sheet/5/tratado-de-lisboa 
obtener el estatuto de refugiado. Una política migratoria estructurada en paralelo, dónde por un lado se puntualiza los derechos para nacionales de terceros países que residen legalmente en la Unión y por el otro, se ejecutan directrices de retorno y expulsión para aquellos migrantes que residen de forma ilegal en la Unión.

Sumado a ello, el discurso institucional de la UE tiene connotaciones negativas en la identificación del sujeto "migrante irregular" como amenaza al bienestar y la seguridad de los ciudadanos comunitarios, en el contexto de la lucha contra la inmigración ilegal. Como bien apunta Rea (2006, p. 160) la política migratoria europea destaca por el énfasis manifiesto a la "otredad" definida desde el derecho de extranjería y la construcción de categoría de migrantes desde su identidad, que recae en el eufemismo de nacionales de terceros países para referirse al extranjero de fuera de la UE. Una gestión de la política migratoria que ha traído en general pérdida de derechos para las personas migrantes, donde las únicas medidas que parecen aprobarse sin objeción entre los Estados miembros son las relacionadas al aumento de seguridad, control y expulsión de migrantes irregulares del territorio europeo. Una política migratoria que define el éxito de forma numérica, tanto en la contabilidad de reducción de llegadas y expulsión de "migrantes irregulares" del territorio comunitario, como en el aumento de acuerdos migratorios de readmisión y cooperación con terceros países, en la lucha contra la inmigración irregular ${ }^{11}$.

La pretendida armonización de la política migratoria en el marco de la integración del proyecto europeo no es precisamente una política común de inmigración y asilo, como bien objeta Rea (2006, p. 159) sino que la europeización de la política pública migratoria está aún en proceso de formación, mayormente en lo que respecta a la integración de los inmigrantes. Así, el ámbito de integración de los migrantes legales queda en el terreno de la soberanía de los Estados, limitándose la UE a establecer prioridades políticas y medidas para ayudar a los gobiernos, sin inmiscuirse en sus leyes nacionales (COM, 2016, 377 final). Una carencia de directrices comunes a los Estados miembros, en un ámbito fundamental como es el de la integración de migrantes, que contrasta con el raudal de políticas comunes de control, persecución y retorno forzado de migrantes en situación irregular en la UE.

\footnotetext{
11 Política de migración de la UE. Recuperado en: https://www.consilium.europa.eu/es/policies/migratorypressures/ (revisado 6/07/2021)
} 
Han pasado muchos años desde los Programas de La Haya y Estocolmo y el procedimiento común de asilo propuesto en el Programa de Tampere, aún sigue esperando que los Estados miembros se pongan de acuerdo y aprueben las medidas de reforma del SECA, entre otras medidas, para lograr un verdadero sistema común de asilo, dónde se respeten los derechos y la dignidad de las personas que acuden a la UE en busca de protección internacional. Propuestas todas, que requieren de una gran cooperación de parte de los Estados miembros y que están regidas por el principio de solidaridad y reparto equitativo de la responsabilidad en el marco de las políticas sobre controles de las fronteras, asilo e inmigración. Puesto que, tanto la cuestión migratoria como la acción exterior son ámbitos de actuación propios de la soberanía nacional de los Estados, la competencia compartida entre Estados miembros y las instituciones europeas en este aspecto, hace que se planteen controversias en cada decisión de la UE.

Sin duda alguna, ha sido la falta de solidaridad que prima en los intereses individuales y la resistencia de los Estados miembros a ceder soberanía - aun cuando los intereses comunes lo requieren - el detonante de la problemática en la gestión de los temas migratorios en la UE y la causa principal por la que los Estados miembros no han llegado a un acuerdo sobre cómo debería ser el SECA, comprendido en una política migratoria exitosa en la UE. Si se toma este principio de solidaridad como eje fundamental de la toma de decisiones para llegar a un acuerdo entre los Estados, estipulado en la propia integración de la UE, estaríamos hablando de una "crisis de integración europea” y no de una "crisis migratoria" en la UE. Una crisis de integración europea que data de los orígenes mismo del proyecto integrador del continente europeo y que pone por encima intereses individuales que poco tienen que ver con el interés en reforzar la solidaridad en Europa, con el que fue inspirado la firma del TUE en 1992. 


\section{Referencias}

ACNUDH. (2013). Estudio regional: administración de las fronteras periféricas de la Unión Europea y sus repercusiones sobre los derechos humanos de los migrantes. (A/HRC/23/46).

Bauman, Z. (2016). Extraños llamando a la puerta. (Santos Mosquera. A, trad.)

Barcelona: Ediciones Paidós. Estado y Sociedad.

Comisión Europea (2015). Una Agenda Europea de Migración. Comunicación de la Comisión Europea al Parlamento Europeo, al Consejo, al Comité Económico y Social Europeo y al Comité de las Regiones. Bruselas, 13/5/2015, COM (2015) 240 final.

Consejo Europeo (1999). Tampere. Conclusiones de la Presidencia. Recuperado de: http://www.consilium.europa.eu/ueDocs/cms_Data/docs/pressdata/es/ec/oo 200-r1.es9.htm (Revisado el 6/7/2021).

Consejo Europeo (2005). El Programa de la Haya: consolidación de la libertad, la seguridad y la justicia en la Unión Europea. (2005/C 53/01).

Consejo Europeo (2010). Programa de Estocolmo. Una Europa abierta y segura que sirva y proteja al Ciudadano. (2010/C 115/01).

Consejo Europeo (2018). European Council conclusions. EUCO/2018. Recuperado en: https://www.consilium.europa.eu/en/press/pressrelleases/2018/06/29/20180628-euco-conclusions-final/

Consejo Europeo (2019). Proteger a los ciudadanos y las libertades en Una nueva agenda estratégica (2019-2024).

Cordero, A. (18 de julio de 2020). Termina sin acuerdo la primera jornada de la cumbre de la Unión Europea. France24. https://www.france24.com/es/20200718-unioneuropea-cumbre-holanda-espana-italia-covid19-presupuestos

De Lucas, J. (2002). La herida original de las políticas de inmigración. A propósito del lugar de los derechos humanos en las políticas de inmigración. Isegoría, 26, 59-84.

Friese, H. (2005). La otredad de Europa. Política y Sociedad, 41(3), 99-112.

Fonseca Morillo, F. J. (2001). Los derechos de los nacionales de terceros países en la Unión Europea: situación jurídico-política tras la proclamación de la Carta de los Derechos Fundamentales de la Unión. Revista Cidob D'afers Internacionals, 53. Serie Ciudadanía Europea e inmigración, 77-95.

García Andrade, P. (2015). La acción exterior de la Unión Europea en materia migratoria. Un problema de reparto de competencias. Valencia: Editorial Tirant lo Blanch. 
Goig Martínez, J. M. (2017). La política común de Inmigración en la Unión Europea en el sesenta aniversario de los Tratados de Roma (O la historia de un fracaso). Revista de Derecho de la Unión Europea, 32, 71-111.

Gsir, S. (2013). Los nuevos trabajadores migrantes en Europa. El surgimiento de una política común de inmigración laboral. Revista Latina de Sociología, 3, 94-113.

Mavrouli, R. (2019). The challenge of today's Area of Freedom, Security and Justice: a re-appropriation of the balance between claims of national security and fundamental rights. Freedom, Security \& Justice: European Legal Studies, 2, 90-119.

Núñez Villaverde, J. A. (2016). UE-Turquía: negociación obscena con los desesperados. Blog Real Instituto Elcano.

Parlamento Europeo (2018). EU asylum, borders and external cooperation on migration. Recent developments. (PE 621.878).

Parlamento Europeo (2019). Asilo y migración en la UE: cifras y hechos. Recuperado en: https://www.europarl.europa.eu/news/es/headlines/society/20170629STO786 30/asilo-y-migracion-en-la-ue-cifras-y-hechos

Parlamento Europeo (2020). Informe sobre la protección de los derechos humanos y la política exterior de la Unión en materia de migración (2020/2116(INI))

Pinyol, G. (2018). Hacia una política europea de inmigración integral: ¿̇reto o mito? En Closa, C. y Molina, I. (Coords.), El futuro de la Unión Europea. Informe Elcano, 23, 75-90.

Rea, A. (2006). La europeización de la política migratoria y la transformación de la otredad. Revista Española de Investigaciones Sociológicas, 116, 157-183.

Sanahuja, J. A. (2016). La Unión Europea y la crisis de los refugiados: fallas de gobernanza, securitización y "diplomacia de chequera” en M. Mesa (Coord.) Retos inaplazables en el sistema internacional (pp. 71-105). Anuario CEIPAZ (2015-2016).

Sánchez Margalef, H. (2020). Solidaridad y coronavirus: ¿el fin del europeísmo naif? en $C I D O B$. Mayo, 2020.

Unión Europea (1992). Tratado de la Unión Europea (TUE) Tratado de Maastricht. (92/C $191 / 01)$.

Unión Europea (1997). Tratado de Ámsterdam. (97/C 340/01).

Unión Europea (2010). Versión Consolidada del Tratado de Funcionamiento de la Unión Europea (TFUE). Tratado de Lisboa (2009).

Unión Europea (26/10/2012). Carta de los Derechos Fundamentales de la Unión Europea (2012/C 326/o2). Diario Oficial de la Unión Europea. 
Zamora, J. A. (2017). Los movimientos migratorios de los refugiados: un análisis a la luz de la teoría crítica. Revista Eletrônica de Educação, 11(2), 303-315.

Zapater Duque, E. (2010). La dimensión exterior del espacio de libertad, seguridad y justicia en el Programa de Estocolmo: el reto de la integración y de la coherencia, en M. Pi Llorens y E. Zapater Duque (Coord.) ¿Hacia una Europa de las personas en el espacio de libertad, seguridad y justicia? Madrid. 


\section{Anexo Unión Europea (orden cronológico)}

Directiva 2002/90/CE del Consejo de 28 de noviembre de 2002 destinada a definir la ayuda a la entrada, a la circulación y a la estancia irregulares. Diario Oficial de las Comunidades Europeas (5.12.2002)

Directiva 2004/38 del Parlamento Europeo y del Consejo, relativa al derecho de los ciudadanos de la Unión y de los miembros de sus familias a circular y residir libremente en el territorio de los Estados miembros. por la que se modifica el Reglamento (CEE) $\mathrm{n}^{\circ}$ 1612/68 y se derogan las Directivas 64/221/CEE, 68/360/CEE, 72/194/CEE, 73/148/CEE, 75/34/CEE, 75/35/CEE, 90/364/CEE, 90/365/CEE y 93/96/CEE (29.04.2004). Diario Oficial de la Unión Europea.

COM (2006) 735 final. Comunicación de la Comisión al Consejo y al Parlamento

Europeo. El Planteamiento global sobre la migración un año después: Hacia una política global europea en materia de migración. Bruselas, 30.11.2006.

Directiva 2008/115/CE del Parlamento Europeo y del Consejo de 16 de diciembre de 2008, relativa a normas y procedimientos comunes en los Estados miembros para el retorno de los nacionales de terceros países en situación irregular. Diario Oficial de la Unión Europea 24.12.2008.

Directiva 2009/52/CE del Parlamento Europeo y del Consejo de 18 de junio de 2009 por la que se establecen normas mínimas sobre las sanciones y medidas aplicables a los empleadores de nacionales de terceros países en situación irregular. Diario Oficial de la Unión Europea 30.6.2009.

Directiva 2011/98/UE del PE y del Consejo por la que se establece un procedimiento único de solicitud de un permiso único que autoriza a los nacionales de terceros países a residir y trabajar en el territorio de un Estado miembro y por la que se establece un conjunto común de derechos para los trabajadores de terceros países que residen legalmente en un Estado miembro. 13 de diciembre de 2011.

COM (2011) 743 final. Comunicación de la Comisión al Parlamento Europeo, al Consejo, al Comité Económico y Social Europeo y al Comité de Las Regiones. Enfoque Global de la Migración y la Movilidad. \{SEC (2011) 1353 final\}. Bruselas, 18.11.2011.

COM (2011) 76 final. Communication from the Commission to the European Parliament and the Council. Evaluation of EU Readmission Agreements. Bruselas, 23.2.2011.

Decisión (UE) 2015/1601 del Consejo (22 de septiembre de 2015) por la que se establecen medidas provisionales en el ámbito de la protección internacional en beneficio de Italia y Grecia. Diario Oficial de la Unión Europea 24.9.2015.

COM (2015) 679 final. Progress Report on the Implementation of the hotspots in Italy. 
Strasbourg, 15.12.2015.

COM (2015) 678 final. Progress Report on the Implementation of the hotspots in

Greece. Strasbourg, 15.12.2015.

Reglamento (UE) 2016/399 del PE y del Consejo por el que se establece un Código de normas de la Unión para el cruce de personas por las fronteras (Código de fronteras Schengen).

Reglamento (UE) 2016/1624 del PE y del Consejo sobre la Guardia Europea de Fronteras y Costas, por el que se modifica el Reglamento (UE) 2016/399 del PE y del Consejo y por el que se derogan el Reglamento (CE) 863/2007 del PE y del Consejo, el Reglamento (CE) 2007/2004 del Consejo y la Decisión 2005/267/CE del Consejo. Septiembre, 2016.

COM (2016) 731 final. Reglamento del PE y del Consejo por el que se crea un Sistema Europeo de Información y Autorización de Viajes (SEIAV) y se modifican los Reglamentos (UE) 515/2014, (UE) 2016/399, (UE) 2016/794 y (UE) 2016/1624. Bruselas, 16.11.2016.

COM (2016) 377 final. Plan de acción para la integración de los nacionales de terceros países. Comunicación de la Comisión al PE, al Consejo, al Comité Económico y Social Europeo y al Comité de las Regiones. Estrasburgo, 7.6.2016.

COM (2016) 120 final. Comunicación de la Comisión al Parlamento Europeo, al Consejo Europeo y al Consejo. Restablecer Schengen - Hoja de ruta. Bruselas, 4.3.2016.

COM (2016) 197 final. Hacia una reforma del Sistema Europeo Común de Asilo y una mejora de las vías legales a Europa (Bruselas, 6.4.2016).

COM (2016) 270 final. Reglamento del Parlamento Europeo y del Consejo por el que se establecen los criterios y mecanismos de determinación del Estado miembro responsable del examen de una solicitud de protección internacional presentada en uno de los Estados miembros por un nacional de un tercer país o un apátrida (texto refundido). Bruselas, 4.5.2016.

COM (2016) 85 final. Comunicación de la CE al PE y al Consejo sobre el estado de ejecución de las medidas prioritarias en el marco de la Agenda Europea de Migración. Bruselas, 10.2.2016.

COM (2016)144final. Informe de la Comisión al Parlamento Europeo y al Consejo. Plan de acción conjunto UE-Turquía - Tercer informe de ejecución. Bruselas, 4.3.2016.

COM (2017) 200 final. Comunicación de la Comisión al Parlamento Europeo y al Consejo relativa a una política de retorno más eficaz en la Unión Europea - Un plan de acción renovado. Bruselas, 2.3.2017.

COM (2017) 570. Comunicación de la Comisión al Parlamento Europeo y al Consejo 
sobre la protección y el refuerzo de Schengen. Bruselas, 27.9.2017.

Reglamento (UE) 2019/818 del PE y del Consejo relativo al establecimiento de un marco para la interoperabilidad entre los sistemas de información de la UE en el ámbito de la cooperación policial y judicial, el asilo y la migración y por el que se modifican los Reglamentos (UE) 2018/1726, (UE) 2018/1862 y (UE) 2019/816. (20 de mayo de 2019).

COM (2020)115 final. Comunicación de la Comisión al Parlamento Europeo, al Consejo Europeo y al Consejo. COVID-19: Restricción temporal de los viajes no esenciales a la UE. Bruselas, 16.3.2020. 